\title{
LA CONSULTA DE 14 DE JULIO DE 1777 Y EL LIBRE COMERCIO: EL DECISIVO VOTO DEL CONSEJERO MAGALLÓN
}

\author{
Antonio García-Baquero González \\ Universidad de Sevilla
}

\section{RESUMEN}

Este artículo profundiza en la gestación del Reglamento Le Libre Comercio (1778), a partir del análisis del informe de Fernando Magallón, consejero de Indias.

Palabras clave: España, Siglo XVIII. Reglamento de Libre Comercio. Informe Magallón.

\section{$\underline{A B S T R A C T}$}

This article offers new perspectives of the Commerce Free's Reglament (1778), making clear the roll of Fernando Magallon, of Conseil of Indias, in the gestation of this Reglament. In the context for the elaboration of Reglament, the Magallon's Informe is analysed, revealing the economic and historic values of Magallon"s thoughts.

Keywords: Spain, XVlII th ${ }^{\text {th }}$ century, Commerce Free's Reglament, Magallon's Informe.

"No se conoce aún el proceso genético de la legislación indiana bajo Carlos III... se ignora gran parte de la múltiple colaboración más o menos directa que la hizo posible... El día en que se aborde a fondo el estudio de la génesis de estas leyes quedaremos asombrados de la multiplicidad de colaboraciones de profesionales y aficionados; de la prolija abundancia de ideas sugeridas aquí y allá; de la nube de proyectos, representaciones, dic. támenes y consultas que se aprovecharon en la construcción de toda esta serie de disposiciones". Muñoz Pérez, J: "La idea de América en Campoinanes".

Anuario de Estudios Americanos, X (1953), p. 239. 
En el estado actual de la investigación, resulta bien conocido el papel, en verdad clave y fundamental, que desempeñó Tomás Ortiz de Landázuri en la gestación y puesta en práctica del proceso legislativo-reformista aplicado al comercio colonial durante el reinado de Carlos III. En efecto, ya en 1947, J. Muñoz Pérez publicó un esclarecedor articulo dando a conocer el famoso "informe" elaborado por Ortiz de Landázuri en diciembre de 1776 y que, según demostraba, se trasladó, prácticamente en su integridad, al texto definitivo del Reglamento $y$ Aranceles para el Comercio Libre de España a Indias de 12 de octubre de 1778'; con posterioridad, otros trabajos han venido a ratificar ese indudable protagonismo, sacando, asimismo, a relucir su destacada participación tanto en la elaboración del Decreto y Real instrucción de $\mathbf{1 7 6 5}$ para el libre comercio con las islas de Barlovento como en la reanudación, a partir de 1771, del programa reformista, tras el parón sufrido durante la etapa caracterizada por Varela Marcos como "el intervalo de espera real"'. Ahora bien y en el presente trabajo, mi intención no es la de volver a incidir sobre la figura o la tarea realizada por Ortiz de Landázuri sino dar a conocer el papel, a su vez decisivo, que en la reunión "plenísima" celebrada por el Consejo de Indias el 14 de julio de 1777 y en la que se dio luz verde a la promulgación del Reglamento de 1778 , jugó otro personaje sobre el que, hasta ahora, apenas si había reparado la historiografía especializada en el tema. Me refiero, concretamente, a Fernando Magallón y Andrés, el único de los siete consejeros que emitieron su opinión por escrito en dicha reunión que votó a favor del informe presentado por Ortiz de Landázuri y, por tanto, de la ampliación del libre comercio al resto de los dominios españoles en Hispanoamérica, con excepción de Nueva España y Venezuela. En realidad, Muñoz Pérez, en el trabajo más arriba citado, se hizo eco de tal circunstancia pero limitándose a señalar que "cuando los ministros se reunieron para emitir votos, el comercio libre solo tuvo un voto decidido en su favor: el de don Fernando Magallón"3. Sin embargo, Magallón no se limitó, simplemente, a dar su asentimiento en aquella "consulta" a las propuestas contenidas en el escrito de Ortiz de Landázuri acerca de la ampliaión del libre comercio sino que acompañó su voto favorable con todo un

\footnotetext{
"MUÑOZ PÉREZ, J: "La publicación del Reglamento de Comercio Libre de Indias de 1778", Anuario de Estudios Americanos, Tomo IV (1947), pp. 615-664; en especial, pp. 644-650.

"Vid. al respecto, entre otros: REAL DÍAZ, J. J., Las ferias de Jalapa. Sevilla, 1959; VARELA MARCOS, J., "El primer Reglamento para el Libre Comercio con América: su génesis y fracaso", Anuario de Estudios Americanos, Tomo XLVI (1989), pp. 143-168; del mismo autor: "El comercio libre americano y sus repercusiones en España y América", en Historia de España y América, Tomo Xl-2, Madrid, 1989, pp. 325-56; LLOMBART, V., Campomanes, economista y politico de Carlos III. Madrid, 1992; GARCIA-BAQUERO GONZÁLEZ, A., "Ortiz de Landázuri y la reanudación del proceso reformista: el informe de 20 de noviembre de 1771", en Entre Puebla de los Ángeles y Sevilla. Homenaje al Dr. José Antonio Calderón Quijano. Sevilla, 1997, pp. 403-420; del mismo autor, "Libre comercio y fiscalidad: las propuestas de reforma de Ortiz de Landázuri", Jahrbuch für Geschichte von Staat, Wirtschaft und Gesellschaft Lateinamerikas, Band 34 (1997), pp. 159-181.

${ }^{3}$ MUÑOZ PÉREZ, J., "La publicación del Reglamento...", Op. cit. p. 649.
} 
corpus de reflexiones personales en torno a esa materia que, en el posterior "acuerdo" elaborado por el propio Consejo, se calificaron de "esenciales" para los fines que se pretendian. Lo que se hizo constar exactamente en el texto de dicho "acuerdo" fue que, pese a los votos contrarios a "la libertad de comercio" emitidos por seis de los consejeros consultados (M. Lanz de Casafonda, J.A. de la Cerda, M. Romero, J.P. Agüero, R. Antunez y Acevedo y P. de Rada),

"el Consejo, sin embargo, desputes de haber examinado con toda madurez el asunto, ha creido deberse conformar en lo sustancial con el sentir del Contador General, el dictamen de los dos Fiscales de Y.M. y con las reflexiones que contiene el voto de Magailón, en que opinándose a favor de la libertad de Comercio, se proponen yarias providencias esenciales que deberán tomarse al mismo tiempo para que el nuevo sistema que se establezca surta los buenos efectos $y$ grandes ventajas que se pueden prometer de él ${ }^{\prime 4}$.

En efecto, el voto al que aquí se alude es, en realidad, un largo y razonado escrito (consta de 35 folios), en el que Fernando Magallón, además de juzgar favorablemente el informe presentado por Ortiz de Landázuri, incluyó, como parte fundamental de su dictamen, toda una serie de "prevenciones y providencias", que deberían acompañar la puesta en ejecución de las propuestas del contador y sin las que, a su juicio, la nueva política del libre comercio que auspiciaba el gobierno difícilmente podria alcanzar los objetivos que perseguía. Me ha parecido, por ello, que podría ser de interés dar a conocer este texto, reincidiendo, asi, nuevamente, en aquella línea de investigación que en su día nos propusiera Muñoz Pérez, instando a los especialistas a rastrear y tratar de sacar a la luz todas aquellas otras colaboraciones (ya fuesen obra de profesionales o de aficionados) que fueron aprovechadas y utilizadas para poner en pie la nueva política del libre comercio y que la historiografía había mantenido en la oscuridad, deslumbrada por los protagonismos más oficiales y visibles. Por consiguiente y en clara sintonía con esa llamada, la finalidad del presente trabajo no es otra que la de poner de relieve la decisiva y, hasta ahora, poco menos que ignorada intervención que, con el escrito con que acompañó su voto, tuvo Fernando Magallón en la trascendental "consulta" del 14 de julio de 1777, insertando, así, de paso, su nombre en la nómina de los "autores" de la legislación reformista aplicada bajo Carlos III al tráfico de la Carrera.

"Texto del "Acuerdo" de la Consulta celebrada el 14 de julio de 1777. Archivo General do Indias (A.G.I), Sec. Indiferente General, leg. 2409; otra copia en Indiferente General, leg. 2759. 


\section{1.-Apuntes biográficos-profesionales sobre Fernando Magallón y Andrés (Tarazona, 1724-Parma, 1781)}

Según acabamos de reseñar, Fernando Magallón es un personaje del que se puede decir que, hasta el momento, ha pasado prácticamente desapercibido para la historiografia especializada en el estudio del libre comercio. Tanto es así que, si exceptuamos la mera referencia que hizo Muñoz Pérez al hecho de haber sido el único consejero que se mostró partidario de la ampliación del libre comercio en la "consulta" de 1777, no contamos con ninguna otra noticia que lo relacionara de forma directa o que tan siquiera aluda a su participación en la génesis de cualquiera de las diferentes medidas legislativas que informaron la nueva política de liberalización del tráfico de la Carrera. Bien es verdad que se sabía que en 1773 (24 de junio) fue designado "consejero supernumerario" del Consejo de Indias, con opción a ocupar la primera plaza efectiva de capa y espada que quedase vacante, lo que sucedió al año siguiente ( 2 de junio de 1774) y que se mantuvo en dicho cargo por espacio de seis años, hasta el 24 de abril de 1780 , fecha en que fue nombrado "ministro plenipotenciario" en el ducado de Parma, guardando los honores debidos a los consejeros de Indias(6). Pero el hecho de ser miembro del Consejo de Indias no tenía que presuponer, necesariamente, que hubiese participado de forma activa y directa en el proceso reformista y desde luego, G. Bernard (que es a quien debemos la anterior información), en la brevísima reseña biográfica que incluye de nuestro personaje, no aporta tampoco ningún otro dato que apunte en esa dirección. A mayor abundamiento, si recurrimos al repertorio biográfico que sobre los diplomáticos españoles del siglo XVIII ha publicado recientemente D. Ozanam, las noticias que añade a las reseñadas sobre el curriculum profesional de Magallón inciden, en su totalidad, en su faceta de funcionario adscrito a la Primera Secretaría de Estado. Concretamente recoge su entrada en dicha Secretaría, como of icial $7^{\circ}$, en 1758 ( 18 de abril) y sus traslados, en 1763 , siendo ya oficial $4^{\circ}$, primero a Londres ( 8 de abril), en calidad de secretario de embajada y, poco más tarde ( 2 de junio), a París, destino en el que ejerció como encargado de negocios en varias ocasiones ${ }^{6} \mathrm{y}$ desde el que fue, asimismo, promocionado a ministro supernumerario del Consejo Indias, si bien con la orden de permanecer en dicha legación hasta el arreglo definitivo de ciertos asuntos en curso de negociación y resolución en aquellos momentos con Francia?. Así se lo hizo saber Grimaldi, en una carta fechada en Aranjuez el 21 de junio de 1773, en la que le advertía que aunque el nuevo embajador, pronto a incorporarse a dicho

\footnotetext{
'Desde la partida de Grimaldi -24-IX-1763- hasta la llegada del conde de Fuentes -21-Il-1764-, durante una larga ausencia de este último -entre el 14-X-1764 y el 16-VI-1766- y de nuevo, desde la marcha de Fuentes -10-IX-1772- hasta la llegada del conde de Aranda -8-IX-1773-.

${ }^{7}$ Los datos relativos a esos nombramientos, cfdo OZANAM, D., Les diplomates espagnols du XVIII siècle. Introduction y répertoire biographique (I700-I808). Madrid-Bordeaux, 1998, pp.334-5.
} 
destino, el conde de Aranda, había nombrado un nuevo secretario (Heredia), "por ahora" debia permanecer en Paris, con objeto de "seguir el asunto de los limites entre España y Francia y el del arreglo de los articulos de la Convención de $1768^{\circ}$, caminando de acuerdo en uno y otro con el conde de Aranda, que en caso necesario auxiliaria con su influjo los pasos que VS. tuviese que dar para el éxito de estos dos importantes negocios"s.

Ahora bien, la orden de permanecer en París parece ser que vino también determinada por el deseo de Grimaldi de tener alguien de su confianza, como era Magallón, cerca del conde de Aranda. Esto, al menos, es lo que se desprende de una carta dirigida por el embajador danés en la capital francesa, Saint Saphorin, a su Corte y en la que afirmaba que "el conde de Grimaldi y el Rey, que detestan al conde de Aranda y no se fian de él, han hecho que, con el pretexto de los asuntos de fronteras en los Pirineos, permanezca en París el anterior secretario de embajada Sr. Magallón. Este Señor es el principal canal secreto que tienen (aquellos) con el duque d'Aiguillon aunque se haya nombrado otro secretario a petición del conde de Aranda"io.

Sea por una u otra razón, lo cierto es que, pese a su nombramiento, en 1774 , como ministro efectivo del Consejo de Indias, Magallón permaneció en París hasta fines del mes de febrero de 1775, fecha en que escribió a Grimaldi solicitándole permiso para abandonar la capital francesa, una vez que ya se había firmado el nuevo convenio en que quedaban "ajustados" los artículos que complementaban, aclaraban y corregian lo acordado en materia comercial en la Convención de $1768^{11}$ y que el asunto de los limites fronterizos en los Pirineos navarros quedaba solo pendiente de su definitiva ratificación en Madrid; asimismo y en esa carta, solicitaba también permiso para, antes de volver a España, rea-

\footnotetext{
${ }^{8}$ Se refiere concretamente a la "Convención entre las coronas de España y Francia para explicar y ampliar el artículo 24 del pacto de familia en punto a navegación, comercio maritimo y visitas de embarcaciones, ajustada y firmada en Madrid el 2 de enero de 1768". Texto integro de la misma en CANTILLO, A. de, Tratados, convenios y declaraciones de paz y de comercio que han hecho con las potencias extranjeras los monarcas españoles de la Casa de Borbón desde el año de 1700 hasta el dia. puesto en orden e ilustrados muchos de ellos con la historia de sus respectivas negociaciones. Madrid, 1843 , pp. $509-516$.

'De Grimaldi a Magallón, Aranjuez, 21-V1-1773. Expediente personal de D. Fernando Magallón. Archivo Histórico Nacional, Sec. Estado, leg. 3427 (2). Debo esta información y la que sigue referida a este mismo expediente a la generosa amabilidad del prof. Jesús Pradells Nadal, a quien desde aquí expreso mi más sincero reconocimiento.

in Cfdo. OLAECHEA, R. y FERRER BENEMELI, J. A., El conde de Aranda. Mito y realidad de ton politico aragonés. 2 vols. Zaragoza, 1978, vol I, pp. 47-8. De esta obra hay una segunda edición, en un solo volumen, Zaragoza, 1998.

"En efecto, dicho convenio se firmó en Versalles, por los plenipotenciarios de España y Francia, el 27 de dicjembre de 1774; constaba de 23 artículos encaminados tanto a reprimir el contrabando como a que "sirvan de suplemento, explicación y corrección del convenio de 2 de enero de 1768". El texto de dicha Convención en CANTILLO, A., Tratados, convenios y declaraciones..., Op. cit, pp. 523-526.
} 
lizar un viaje por Inglaterra y Holanda y tomar las aguas en Spá, al objeto de "destruir las obstrucciones que padezco"'2.

Tras su regreso a Madrid, pasó a ocupar su plaza como ministro de capa y espada del Consejo de Indias, cargo en el que se mantuvo hasta el 24 de abril de 1780 , fecha en que fue nombrado por Floridablanca ministro plenipotenciario en el ducado de Parma. Las credenciales para el infante D. Fernando, duque de Parma, se le remitieron el 6 de septiembre de 1780, con la advertencia de que "No se ha formado instrucción general para VS. por contemplar le bastará seguir en lo general la que llevó el marqués de Villel y encontrará VS. en la Secretaría de su Ministerio; para lo que se ofrezca se harán a VS. las prevenciones correspondientes" ${ }^{\prime 3}$.

Su incorporación al nuevo destino se produjo el 13 de septiembre de 1780 , donde murió apenas un año más tarde, el 14 de diciembre de 1781, a causa de un vómito de sangre (padecía tuberculosis) y cuando contaba 56 años de edad. La Gaceta di Parma (en el número correspondiente al 21-XII-1781) publicó un caluroso elogio fúnebre de su persona, presentándole como miembro de una nobilísima familia aragonesa, poseedor de una sólida formación, caballero de la orden de Malta y académico por partida triple (de la Historia, de la Lengua y de Bellas Artes), destacando, asimismo, su larga "hoja de servicios" como diplomático y que avaló sus nombramientos, primero como consejero de Indias y, más tarde, como plenipotenciario en Parma; la reseña concluía con una descripción de su

\footnotetext{
${ }^{12}$ Cfdo. De Magallón a Grimaldi, París, 27-II-1775. A.H.N., Sec. Estado, leg. 3427 (2); el permiso para el viaje se le concedió el 13-III-1775. Cfdo. Ibídem.

"De Floridablanca a Magalón, El Pardo, 6-IX-1780. A.H.N., Sec. Estado, leg. 3427 (2). En cualquier caso, el 12 de diciembre de ese mismo año, Floridablanca escribió una carta a Magallón y en la que, tras excusarse por no haber dado más pronta respuesta a "la estimable confidencial de VS" y desearle que "los fríos de Lombardia no le sean tan contrarios como los de Madrid", añadía lo que sigue: "VS. habrá visto el buen carácter de ese Príncipe, con quien es muy fácil con-servar la más sincera y más amable correspondencia. La señora tiene momentos; basta prescindir cuanto se pueda de sus cosas y consolar al marido como lo hace todo hombre honrado, sin exagerar las imperfecciones de su mujer ni aumentar los disgustos y estrechuras de un lazo indisoluble. El Ministro de Francia afectará superioridad y su mujer es bien extraordinaria, o como dicen los italianos, curiosa aunque no limpia. VS. sabrá despreciar sin jactancias ni etiquetas esas miserables presunciones e intriguillas, tomando su partido indiferencia y abstracción de chismes. ¿Que diré yo a VS. que no haya comprendido mejor en los pocos días que está en esa Corte?. Sin embargo, le aconsejaré que en nada se ligue y se tome tiempo para preguntar cuando se trate de hacer algo con acuerdo o consentimiento de la España, ya sea relativo al interno, o ya al externo de esos estados. Con esto se arriesgará muy poco de parte de VS. quien si quịere una instrucción formal podrá avisarlo para dirigirsela". De Floridablanca a Magallón, Madrid, 12-XII-1780. Expediente personal. A.H.N. Sec. Estado, leg. 3427 (2).
} 
enfermedad, muerte y entierro, incluyendo, además, una copia de la inscripción de su lápida funeraria ${ }^{14}$.

En definitiva y como ha quedado de manifiesto, en ninguna de las reseñas biográficas que se han hecho de Fernando Magallón existe alusión alguna a que hubiese participado de forma activa y directa, como de hecho lo hizo, en la elaboración de cualquiera de las medidas que, durante su permanencia en el Consejo de Indias, se promulgaron en orden a la liberalización del tráfico con Indias. Tampoco nos consta que, con anterioridad a su adscripción a la Primera Secretaria de Estado, haya ocupado cargo alguno en la administración indiana que le hubiese permitido familiarizarse con la problemática colonial ${ }^{15}$. Todas las noticias inciden, pues, en su faceta de diplomático, de modo que cabe preguntarse de donde le venían los conocimientos que en torno a la reforma y mejora del comercio colonial demuestra en su escrito. Desde luego, si atendemos a algunos de los asuntos que tuvo que atender, durante su estancia en París cono encargado de negocios, cuando menos se puede intuir que ni la temática colonial y ni la comercial le eran en absoluto desconocidas. Por de pronto y con relación al "americanismo" de Magallón, parece ser que intervino en la "negociación" para la incorporación de La Luisiana a la corona española tras la firma de la Paz de París de 1763. Desde luego, esto es lo que se desprende de un escrito que dirigió a Choiseul en 1766, en el que le manifestaba sus quejas por la caótica situación en que se hallaba aquel territorio y que motivó una airada réplica del ministro francés, culpando de tal estado de cosas al gobierno español por no haber tomado aún posesión de dicha colonia, dilación que, en su opinión, habia costado a Francia seis o siete millones de libras. Magallón dio cuenta de esta gestión a Grimaldi, comentándole que "cuando se hizo la cesión no se estipuló nada sabre el tiempo en que se debia tomar posesión...si la colonia es útil hemos perdido el

\footnotetext{
"En efecto, entre otras cosas, la Gaceta decia: "Nato con una penetrazione d"igegno singolere, con una giustezza di mente, con discernimiento sicuro delle cose, che prendera a studiare, dotato di tenacissima memoria, occupato indefenssamente nella d'ogni idioma, area acquistate infinite cognizioni e dell'altro Emisferio, su quella del comercio, nella scienza del Governo, e degli interessi de Principi, nelle amene lettere greche, latine, spagnuole e francesi. Tutti questi ornamenti concorsero, prechè dal Re Carlo Terzo venisse meritatemente nominato Ministro del Supremo Consiglio dell'Indie, e della Real Giunta del Commercio, della Monetazione e dello Miniere, Consigliero della Reale Academia di San Fernando, membro dell 'Academia di Storia e Lingua nazionaie, e di quella delle Belli Arti, per le quali avea una particolar proponsione, congiunta ad un esquisito finissimo gusto". A.H.N., Sec. Estado, leg. $3427(2)$.

15 Desde luego debo señalar que M.A. BULKHOLDER y D.S. CHANDLER no incluyen su nombre en los apéndices IX y X de su obra De la impotencia a la autoridad. La Corona española y las Audiencias en América, 1687-1808 (México, 1984) ni tampoco en su Biographical Dictionary of" Audiencia Ministers in the Americas, 1687-1821 (Westport, Connecticut-London, England, 1982).
} 
provecho; si no lo es, ¿qué razón puede haber para hacernos salir de nuestro paso ordinario y obligarnos a correr tras un paso tan oneroso?"16.

Y, obviamente, es de suponer que esos conocimientos adquiridos en París sobre los asuntos indiano ${ }^{17}$ debieron, razonablemente, incrementarse a raíz de su incorporación al Consejo de Indias aunque no dispongamos de información precisa sobre el particular. En cuanto a los conocimientos que pudiese poseer en materia comercial, ya hemos señalado que, tras su nombramiento como consejero de Indias, una de las razones que le obligaron a permanecer en París fue, precisamente, el encargo recibido de Grimaldi de ajustar y negociar los acuerdos comerciales derivados del Convenio hispano-francés de 1768. Por tanto y tras esta breve incursión en su biografía, demos paso, seguidamente, al texto que presentó en la "consulta" celebrada el 14 de julio de 1777.

\section{2.-EI razonado voto de Fernando Magallón}

De entrada, conviene comenzar reseñando que el texto que aquí vamos a extractar y en el que F. Magallón expresó su voto favorable tanto al informe presentado por Ortiz de Landázuri como a la ampliación del libre comercio, no es el original por él redactado (de cuya existencia no tenemos constancia documental) sino la copia o "traslado" del mismo incluida en el expediente que resultó de la "consulta" celebrada el 14 de julio de 1777. Sin embargo, hay que aclarar de inmediato que la impresión que se obtiene de su lectura es que se trata de una reproducción, aparentemente literal, del texto escrito por Magallón y en la que el "copista", tal vez para dejar constancia de su labor, se limita, simplemente y al inicio de algunos párrafos, bien a poner en tercera persona el verbo que corresponda o a introducir expresiones tales como "cree Magallón", "le parece a Magallón", etc. Hecha esta advertencia preliminar y como ya se ha adelantado, el texto se compone de dos partes bien diferenciadas a tenor de su contenido y de muy desigual extensión: una primera, que abarca la parte sustancial del mismo (26 de los 35 folios de que consta) y en la que Magallón expone tanto las medidas que deberán acompañar la ampliación del libre comercio (caso de que así se acuerde) como las razones que le llevan a inclinarse en favor de este nuevo sistema frente al antiguo, todavía en vigor; una segunda, más breve ( 9 folios), en la

\footnotetext{
"Cfdo. ARMILLAS VICENTE, J. A., "El "ensueño" americano del conde de Aranda", en J. A. FERRER BENEMELI (Dir) y E. SARAZA y E. SERRANO (Coords), El Conde de Aranda y sil tiempo. 2 vols. Zaragoza, 2000, Vol. Il, pp. 437-62; la cita en p. 443.

i7 Abundando en los conocimientos que sobre el mundo colonial adquirió durante su estancia en París convendria anotar que en el Archivo de Simancas (leg. 6957) se conserva un manuscrito titulado Conversación de D. Fernando Magallón con Bouganville sobre sus viajes a las Malvinas.
} 
que se limita a comentar las propuestas de Ortiz de Landázuri, dando su asentimiento a la práctica totalidad de las mismas aunque, como veremos, no sin alguna que otra reserva ${ }^{18}$; pero, no adelantemos acontecimientos y vayamos por su orden.

Por de pronto, Magallón comienza por calificar el asunto sobre el que se debe pronunciar como "el más grave e importante de cuantos ha habido" y ello, porque, a su juicio, de la decisión que se adopte sobre el mismo "depende, tal vez, la felicidad o la ruina del comercio de América, en que estriba la basa del poder y el crédito de la Monarquia". Es más, se trata de un asunto tan complejo y que abarca tantos ramos, que duda que haya alguien que posea "toda aquella plena e individual instrucción que pide cada uno de ellos para determinar con acierto el principal". Por lo que a él respecta y para poder emitir su voto con pleno conocimiento de causa, entiende que le sería necesario reunir las siguientes condiciones previas:

a) "conocer perfectamente el comercio de Indias y el de Cádiz";

b) "estar menudamente instruido de la situación en que se halla España en punto de fábricas y manufacturas, a fin de poder calcular hasta qué grado es capaz de surtir tan bastas Colonias como las nuestras";

c) "tener una seguridad moral de que no hallándose, como no se halla en el dia, la Nación en estado de suministrar lo necesario al surtimiento de nuestras Colonias, se ocupará el Ministerio Superior, con todo el empeño $y$ celo de que lo cree capaz en multiplicar las manufacturas, en proteger sólidamente el comercio interior del Reino, en sacar la agricultura y las artes del abatimiento en que se hallan, en aumentar la población, en facilitar la comunicación interior y la conducción de géneros y frutos a los puertos por medio de canales, de rios navegables y de caminos, pues si no se promueven ardientemente y sin intermisión todos estos objetos, de nada o de muy poco servirán las providencias generales que se tomen en punto de nuestra contratación a la América ni podrá producir buenos efectos cualquier nuevo sistema que se establezca". En realidad, de esos tres puntos es sobre todo este último el que reviste mayor importancia para Magallón, en la medida que, en su opinión, la auténtica carcoma que corroe y destruye aquel comercio y que no es otra que el trato ilicito que practican los extranjeros, "subsistirá siempre, mientras no se ponga la Nación en la Peninsula en estado de suministrar a precios cómodos,

${ }_{18}$ El texto abarca desde el folio 7 vto. de la consulta hasta el 24 vto. Cfdo. A.G.I., Sec. Indiferente General, leg. 2409. Todas las citas textuales que vienen a contimuación Jemiten a esta misma referencia documental, lo que advertimos para evitar una innecesaria proliferación de notas. 
capaces de destruir el contrabando, la mayor parte a lo menos de lo que necesitan nuestras colonias". Buena prueba de ello la constituye, como señala más adelante, lo que nos enseñaba la historia del comercio que practicaban Francia, Inglaterra y Holanda con sus respectivas colonias, comercio que no comenzó a resultarles rentables hasta que promovieron en las metrópolis el desarrollo de la industria, la agricultura y el transporte interior, insistiendo, asimismo, en el papel nada desdeñable que en el florecimiento de sus fábricas jugó también "la introducción ilícita de sus géneros que estaban seguros habian de hacer en nuestras Indias y la necesidad en que nos veiamos de comprarselos en Europa, porque sabian no los teníamos en bastante abundancia en España". Por consiguiente, para Magallón resultaba mcridianamente claro que, mientras no se adoptasen en España medidas capaces de colocar a la industria nacional en situación de proveer a nuestras colonias de esos géneros que ahora había que comprar en el extranjero, "será infundada y vana la esperanza de ver prosperar nuestro comercio a la América". A mayor abundamiento y como apostilla a renglón seguido, "se podrá variar el sistema actual; resultarán, tal vez, de esta variación algunas ventajas pasajeras que nos deslumbren por algín corto tiempo; pero subsistirá siempre el mal radical; las naciones extranjeras conservarán la facilidad de introducir el contrabando en América...y necesitados a cargar nuestras flotas o navios sueltos de mercaderias trabajadas fuera del Reino, pasará forzosamente todo el oro y la plata de la América, como hoy sucede, a los Reinos extranjeros".

Ahora bien, consciente del estado "miserable y abatido" en que se hallaban, en esos momentos, las fábricas y manufacturas españolas considera que "pretender hacer única y exclusivamente todo el comercio de la América es una idea inasequible...y no se deben abrazar jamás ideas quiméricas sin fijarse en las posibles y regulares". Pero es más y con independencia del hecho de que se trate de una meta inalcanzable (aún contando con un futuro desarrollo de nuestra producción industrial), no cree que "fuese una buena política el aspirar a ser dueños exclusivos de todo el oro y plata de las minas" y ello, básicamente, por dos razones fundamentales: primera, por que el resto de las naciones europeas no tardarían en unirse y declararnos la guerra "para despojarnos de muchas de las tierras que producen aquellas minas"; en segundo lugar, porque "nadie ignora el principio de Estado o, por mejor decir; de Cálculo político de Comercio que supone, que como el oro y la plata son unas riquezas de signo y signos por su naturaleza muy durables, cuanto más se multiplican en una Nación, tanto más pierden de su valor y tanto menos objetos y cosas representan". En apoyo de esta segunda razón trae justamente a colación el ejemplo de lo sucedido en España a raíz de la llega- 
da de las primeras remesas metálicas de América, época en que "como se dobló y triplicó el dinero, se dobló y triplicó también el precio de las cosas que se compraban y vendian"; y si con posterioridad, pese a que siguicron creciendo los envios de oro y plata, "ha estado muy lejos de envilecerse su valor a medida de su abundancia", se debió a que estos metales no hicieron "más que pasar rápidamente de nuestras manos a las de los extranjeros", sin duda alguna, "un gran mal para la España" aunque, en su opinión, "hubiera sido igual el que se hubiese experimentado", caso de que ese inmenso raudal de riquezas "no hubiese salido de nuestras manos". Por todo ello y dada su confesada filiación a la teoría cuantitativa del dinero, a lo que debe aspirar España no es a la quimérica idea, en su opinión, de retener aquí los tesoros americanos sino a tratar de "aumentar, cuanto sea dable y hasta el punto que no tenga inconvenientes, los surtimientos a nuestras Colonias"; es decir, evitando los peligros de la inflación.

Partiendo de estos principios generales, Magallón pasa, seguidamente, a tratar la cuestión clave a la que debe dar respuesta y que no es otra que la de pronunciarse acerca de la conveniencia o no de adoptar en el comercio con Indias "el sistema de una entera libertad que se extienda a todas las provincias y vasallos de la Peninsula bajo las reglas que parezcan convenientes y el mudar el método que hasta aqui se ha seguido de hacer las expediciones desde solo el puerto de Cádiz". En esta dirección y antes de entrar en consideraciones de cualquier otro tipo, lo primero que desea señalar que, caso de que se opte por introducir tal mudanza, las circunstancias que concurren en esos momentos son, sin duda, las más favorables, ya que, "el embargo en que se halla hoy con sus colonias la nación inglesa nos deja lugar para obrar con más libertad que podriamos en otro tiempo". Dicho esto y en cuanto a su opinión acerca de la decisión que se debe adoptar, afirma tajantemente que "cuanto más medita sobre el estado y abandono a que se ve reducido nuestro comercio a la América y sobre los inconvenientes del actual sistema, tanto más se inclina a preferir el de un comercio libre, que se extienda bajo ciertas reglas a las demás provincias de España, sin que sea solo el puerto de Cádiz el punto y lugar exclusivo de nuestra contratación a las Indias". Tal opinión se sustenta, según aclara a renglón seguido, en "muchas y poderosas razones", de entre las que hay tres que considera fundamentales y que pasa a desarrollar.

En primer lugar cita el hecho de que "ninguna nación comerciante con colonias ultramarinas se gobierna por el método que nos sirve a nosotros de regla". En efecto y como expone a continuación, lo mismo Francia que Inglaterra y Holanda, dejan en plena libertad a sus vasallos para que participen en sus respectivos comercios ultramarinos, sin apenas sujetar a formalidades la carga y expedición de sus navíos que, además, pueden partir y regresar desde y a los puer- 
tos que estimen convenientes. Este sistema ha dado como resultado que "las islas que tiene Francia en la América septentrional, las cuales pueden reputarse como un punto cotejadas con la inmensa extensión y riquezas de nuestras colonias, producen anualmente cerca de 100 millones de libras, que hacen 20 millones de pesos fuertes; ocupan 600 y más embarcaciones y 18 mil marineros en transportar sus productos a Francia y reciben de la metrópoli por más de 60 millones de libras en diferentes géneros, efectos, negros, etc". Tras aclarar que estos son datos extraídos de las "Memorias y manuscritos originales presentados al Ministerio de Francia" y que el ha consultado personalmente, añade que Inglaterra, por su parte y solo de las islas que posee en el Caribe (es decir, sin contar con las colonias que posee en la América del Norte), obtiene también anualmente "70 millones de libras tornesas, que hacen 14 millones de pesos fuertes, cuyo tráfico y conducción a Inglaterra ocupa de 550 a 560 navios, con más de 14 mil marineros"; y que, asimismo, observaciones similares se podrían hacer a propósito del comercio que hacen los holandeses y los daneses "en las pequeñisimas islas que tienen en la América, cuyo comercio, ocupación de marineria y riquezas que a cada una de estas naciones resulta es casi increible". Ahora bien y como precisa de inmediato, esos beneficios que obtienen estas naciones no provienen, exclusivamente, de la libertad y facilidad con que sus vasallos practican el comercio sino, también y en no menor medida, del hecho de que, a diferencia de lo que le sucede a los españoles, los géneros y mercaderías que introducen en ese tráfico "los sacan de sus propias fábricas y manufacturas". De ahí, pues, que vueIva a recordar que "el Plan de la libertad que conviene establecer no debe jamás separarse del Plan relativo al fomento de las artes y manufacturas...un sistema ha de ser inseparable del otro y así, y no de otra manera, se prestarán un auxilio recíproco".

La segunda razón en que fundamenta la conveniencia de mudar el actual sistema son las nulas ventajas que ha reportado al conjunto del pais "la facultad exclusiva concedida a solo el puerto de Cádiz y a los negociantes matriculados en él, ya que, como es público y notorio, "casi todo el comercio de Indias que se hace por aquel puerto lo disfrutan los extranjeros". Por de pronto, comicnza por calificar a los comerciantes gaditanos de simples "factores y encomenderos de los extranjeros", quienes, además, al comercio que realizan por medio de estos intermediarios, unen el contrabando que hacen desde sus propias colonias, de suerte que, según "han calculado hábiles y experimentados negociantes, de las 50 ó 54 partes en que dividen el comercio de la América, no hacen los españoles de quienes son aquellas posesiones, sino cinco o seis, y toda las demás restantes las hacen los extranjeros, o ceden en su provecho". Tras volver a insistir en que el cuerpo de comerciantes que integran la matrícula de Cádiz "no es otra cosa...que una Compañia de Comercio con privilegio exclusivo, destinada a traficar ella sola con unos paises conocidos, cuyas inmensas ganancias son seguras", pasa a 
cuestionar el por qué esa facultad ha de ser privativa de dicho puerto en lugar de ser compartida por el resto de las provincias y puertos del Estado. Al respecto, comienza por señalar que, aunque se estableciese la libertad, todavía serían muchas las ventajas que le quedarían a Cádiz, "por su buena proporción y bello fondeadero; por estar en una provincia abundante en frutos y caldos; por haber en aquella plaza muchas y ricas casas de comercio y aún mucho más si se deja por ahora como conviene, y seguin se opina en el informe del Contador general, la expedición de flotas". Pero, a todo esto hay que añadir, además y en su opinión, que Cádiz no es una plaza lo suficientemente segura como para "flarla privativa y exclusivamente todos los tesoros, recursos y riquezas de la Nacion". En esta dirección señala los peligros que, en tiempos de guerra, corren las embarcaciones procedentes de América de caer en manos de los enemigos, máxime habida cuenta de la proximidad de Gibraltar, donde los navios ingleses tienen refugio seguro y desde donde pueden entrar y salir a su antojo y bloquear la bahía; también en tiempos de paz, la cercanía de Cádiz a las costas africanas expone estas embarcaciones a los posibles ataques de piratas berberiscos, sin olvidar los estragos que hace el mar en su puerto y que obliga a realizar importantes gastos en su reparación, así como que se trata del puerto "más caro de España, lo que es catusa de ser sus fletes y expediciones costosísimas y la subsistencia y manutención dificil a los que no fueren muy ricos".

Finalmente, la tercera razón que le ha llevado a inclinarse en favor de la adopción del nuevo sistema de libertad es la de "las ventajas que han resultado del comercio libre establecido desde el año 65 para las islas de Barlovento, sin embargo de faltar a aquel establecimiento muchos grados de perfección de que es susceptible". Como puede comprobarse, una vez más vuelve a reafirmarse en su idea matriz de la necesidad de acompañar la implantación del nuevo sistema de libertad comercial con otras medidas complementarias. Por ello y tras señalar que en apoyo de este punto se limita a conformarse con lo que se expone sobre el particular tanto en el informe de Ortiz de Landázuri como en un dictamen del virrey de Santa Fe que obra en poder de todos los consejeros, insiste en que "si hasta ahora no se ha sacado de la utilisima providencia del año 65 todas las ventajas que se hubiera podido, no es defecto de la providencia general sino de no haberla acompañado con algunas particularidades que hubieran podido hacerla completa". Aún así, de lo que no cabía duda, a tenor de la información disponible, es de que el floreciente estado en que se hallaban en aquellos momentos La Habana y toda la isla de Cuba se debía "a la libertad que se les concedió y (que) si se coteja su comercio, abundancia y riquezas actuales con las de tiempos anteriores a esta libertad, no puede dejar de confesarse que hay una considerable diferencia". 
Por consiguiente y en opinión de Magallón, todas las razones que llevaba expuestas probaban, de forma absolutamente convincente, que "debe el Ministerio resolverse a abrazar un sistema contrario al que hasta aqui se ha seguido" y que dicho sistema "no puede ser otro que el del comercio libre, bajo las reglas y precauciones que parecieren convenientes" $\mathrm{y}$, desde luego, incorporando las recomendaciones hechas por él a propósito del fomento de la producción nacional y de la articulación del mercado interior. Con todo, antes de cerrar esta primera parte de su escrito y para reforzar sus alegaciones en favor de la necesidad de cambiar el viejo sistema, opta por añadir una nueva prueba "que aunque extrinseca da mucho peso a este modo de pensar y esta es la autoridad de muchos hombres grandes y ministros de la Nación que han sido de este mismo sentir". Concretamente dos serán los testimonios de autoridad a los que recurra: el Testamento politico o idea de un gobierno católico de José de Carvajal y Lancáster y el Nuevo sistema de gobierno económico para América de José del Campillo y Cossio ${ }^{19}$. De la obra de Carvajal incluye dos largas citas textuales: una primera, en la que Carvajal critica el que denomina "derecho de primogenitura que tiene Cádiz al comercio con Indias", derecho que ejerce sin que las propias autoridades se hayan planteado siquiera el riesgo que supone concentrar todo el comercio en una plaza tan expuesta a los ataques y bloqueos por el enemigo y del que se ha derivado "que todos los dominios del Rey, fuera de Andalucia, están ignorantes de las cosas de nuestras Indias como de la Arabia y Etiopia, con que ni le tienen cariño, ni les dan aprecio ninguna clase de gentes"; y una segunda, en la que define al comercio de Cádiz como de "una compañía informe $y$ mala... donde solo gozan de la negociación de Indias los individuos matriculados", a los que califica de "mancebos de los extranjeros, que comen de sus encomiendas y préstanles el nombre para que hagan su comercio, con que nada profieren si no es lo que les influyen los que les dan de comer". Por su parte y aunque no incluye ninguna cita textual de Campillo, comenta que este era de la opinión de que uno de los principales remedios para sacar una mayor utilidad de nuestras Indias "seria la libertad del comercio y abrir los puertos de Cantabria, Galicia, Cataluña y de otras provincias de España"; asimismo y con referencia a este mismo autor señala que no era partidario de que el gobierno, a la hora de adoptar resoluciones relacionadas con la política comercial, pidiese su opinión a los negociantes particulares y menos aún a los integrantes del Consulado gadita-

\footnotetext{
"De la obra citada de J, Carvajal existen dos ediciones, la primera publicada en la Continuación del Alnacén de Frnitos Literarios o Semanario de Obras Inéditas (Madrid, 1818) y una segunda realizada recientemente por J. M. Delgado Barrado bajo el título José de Carvajal y Lancáster. Testamento politico o idea de un gabierno católico (1745). Córdoba, 1999; por lo que se refiere, a su vez, al Nuevo sistema de Campillo y prescindiendo aquí de la polémica existente acerca de su verdadera autoría, el texto impreso puede consultarse tanto en su primera edición (Madric, 1789) como en dos nuevas ediciones realizadas, respectivamente, por E. Arcila Farias (Mérida-Venezuela, 1971) y M. Ballesteros Gaibrois (Oviedo, 1993).
} 
no, criterio con el que concuerda "porque ni aquel Cuerpo ni los particulares mirarán jamás sino por sus propias ventajas" aunque si cabía, en cambio, solicitar informes particulares de "personas hábiles e imparciales".

Con esto concluye la primera parte de su exposición para entrar, seguidamente, a valorar el informe presentado por Ortiz de Landázuri, que era, en puridad, para lo que se había convocado la "consulta". De nuevo también aquí inicia su exposición advirtiendo con modestia que para poder juzgar, en profundidad y con pormenor, las propuestas que contiene el informe "seria preciso estar versadísimo" en las distintas materias que abarca y "conocerlas por práctica $y$ experiencia"; pese a ello, entiende que "hay entre los remedios propuestos muchos de cuya utilidad e importancia es imposible dudar y que es necesario ponerlos en práctica" aunque, desde luego, "no podrán lograrse todos de una vez...el tiempo y la experiencia enseñan cada dia como se han de ir llevando por grados a su perfección". En cualquier caso y dentro de ese apartado de medidas propuestas por Ortiz de Landázuri y cuya puesta en ejecución, a su juicio, no convendría demorar, incluye las siguientes:

a) extender a todas las provincias españolas el derecho a comerciar directamente con América, señalándose, tanto en la Península como en América, los puertos habilitados a tal efecto;

b) reducir los derechos y simplificar al máximo las formalidades administrativas a cumplimentar en dichos puertos, lo mismo a su salida que a su regreso, por las embarcaciones;

c) favorecer con ciertas "gracias y alicientes" el comercio y la navegación con aquellas zonas de América más pobres y, por ello, menos frecuentadas hasta ahora por el comercio metropolitano;

d) corregir todos los inconvenientes derivados del Proyecto de 1720 。 sencillamente derogarlo;

e) disminuir los derechos con que se gravan las ropas y manufacturas espaniolas recargando, en cambio, las de procedencia extranjera; igualmente que se moderen los derechos sobre el oro, la plata y los géneros procedentes de América, distinguiendo en estos últimos y como señalaba el contador, de una parte entre aquellos que son privativos de nuestras colonias y los que se producen también en las extranjeras y, de otra, entre los que se utilizan como materias primas en nuestras fäbricas y los que son puramente artículos de lujo, adecuándose el monto de la carga impositiva en función de tales circunstancias. Conviene asimismo reseñar que a todo este conjunto de propuestas incluidas, efectivamente, por Ortiz de Landázuri en su informe, Magallón añade, además, la necesidad de 
fomentar por parte del Estado la creación de compañías particulares en todas las provincias españolas pero "sin privilegio exclusivo y sin perjuicio de la facultad que tendria cualquier vasallo de fletar embarcaciones por si solo", ya que, en su opinión, "este medio sería quizás muy provechoso a lo menos a los principios para la unión y seguridad de los capitales y para soportar las pérdidas que podrian ocasionar los accidentes, hasta que cada provincia conociese los parajes y principios sobre los que la convenia girar su particular contratación".

Frente a este conjunto de medidas de inmediata aplicación, hay otras, entre las propuestas por Ortiz de Landázuri, con las que Magallón se muestra sencillamente en desacuerdo o bien las considera, al menos por el momento, inviables. Dentro de este apartado se encuentran:

a) en primer lugar, la propuesta de prohibir, de forma general, que se planten viñas en América, ya que, en su opinión "hay parajes en que ciertamente debe disimularse, como sucede, por ejemplo, en muchos valles de la costa de la Mar del Sur y en el que las mismas leyes promulgadas sobre este punto han disimulado la transgresión por que sus habitantes no tienen ni pueden tener otro modo de subsistir y seria arruinar y despoblar dichos paises el privarles del solo recurso y productos que les da la naturaleza, y asi la regla general que se propone le parece exige en ciertos parajes alguna moderación";

b) en segundo lugar y en sintonía con este punto de vista, aunque está de acuerdo con la propuesta de que se declare libre de derechos la exportación a América de nuestras harinas, sin embargo considera que "no por esto se ha de dejar de animar en América la parte de agricultura que puede contribuir a que se mantengan aquellos vasallos del producto de su propio suelo" y ello por que si bien es cierto que "hay culturas que pudieran tener el riesgo de conducirlas a no depender de la metrópoli. hay algunas que seria muy mala y cruel politica privarlos";

c) en tercer lugar y en relación con la propuesta del contador de declarar libre la introducción de negros en América e ir a buscarlos directamente a Africa, si bien entiende que "sería importantísimo y acarrearia ventajas considerables a la Nación", no por ello deja de considerar "que el estado y posesión en que se hallan las naciones de Europa en aquellas costas, lo hace si no imposible, a lo menos muy dificil; casi todas ellas tienen factorias y establecimientos en los más de los puertos conocidos y dificultosamente permitirian la concurrencia de otra nación"; ahora bien y constatada esta realidad, añade de inmediato que "es a la verdad cosa 
vergonzosa que nosotros que tenemos tanta necesidad de los negros, seamos los ínicos entre las naciones maritimas y negociantes que no hayamos tenido arte ni modo para hacer en derechura este comercio", considerando que un buen ejemplo a seguir sería el que nos proporcionan los portugueses, que van directamente desde el Brasil hasta las costas de Africa para proveerse de esclavos negros, aunque "es quizás' ya tarde para pensar en entrar a la parte con ellos, al menos que algún rompimiento con esta Nación no nos de ocasión de pensar en tomar medidas bien combinadas para despojarlos de aquel tráfico".

Fuera ya de este apartado y en lo que se refiere a la propuesta de Ortiz de Landázuri de continuar, por ahora, realizando el comercio con Nueva España por medio del sistema tradicional de flotas, le parece que es "muy acertada la continuación hasta ver como prueba el nuevo plan de la libertad comercio... y por los grandes inconvenientes que podria traer suprimirlas repentinamente". A mayor abundamiento y en su opinión, "es menester hacer un ensayo del muevo sistema y empezar a ponerlo en ejecución, sin abolir totalmente y de una vez el método actual. La experiencia del bien que vaya resultando, hará ver lo que sucesivamente se pueda adelantar". Ahora bien y continuando con el tema de las flotas, admite que "no tiene la instrucción práctica que se requiere para formar juicio seguro" ni en lo concerniente al reparto de toneladas que se propone del buque de las flotas entre distintos puertos, mientras que éstas subsistan, ni tampoco acerca de los inconvenientes que puede entrañar la obligatoriedad de que los navíos que salgan de esos puertos se unan, en un tiempo preciso y la altura de Canarias, con el convoy principal que habría partido de Cádiz; en cambio, sí advierte que el riesgo que se corre de que a esos navíos que salen de otros puertos se puedan transbordar mercancías de contrabando desde embarcaciones extranjeras que les salgan al paso, antes de unirse al grueso del convoy, exige "que se tomen todas las precauciones y medidas necesarias para evitarlo".

Finalmente y respecto a otras propuestas aún más esenciales, si cabe, como la supresión de los derechos de toneladas, palmeo y otros y su sustitución por sendos gravámenes del $6 \%$ sobre las manufacturas y del $5 \%$ sobre los "frutos de la tierra", excusa también el no pronunciarse, ya que considera que esta es materia que exige "conocimientos prácticos mercantiles muy individuales que no tiene y sería una especie de temeridad el arriesgarse a pronunciar decisivamente su dictamen sobre estos particulares".

Magallón concluye su escrito afirmando que "en un asunto de tanta naturaleza, si se acierta en las medidas se contribuirá en gran parte al poder y la felicidad de la Monarquia pero que si por falta de informes $y$ de combinaciones 
seguras se establece mal el sistema principal, resultarán graves e irreparables daños a los particulares y a la Nación".

En definitiva y como hemos podido comprobar, Magallón, lejos de limitarse a informar, como incialmente se le solicitó, acerca de las propuestas que contenía el escrito de Ortiz de Landázuri, se extendió (y nunca mejor utilizado el verbo) en toda una serie de consideraciones en torno a los "prerrequisitos" que deberían acompañar la ampliación del libre comercio y a las que se podría calificar, como mínimo, de "realistas", ya que abogaban por una adecuación de dicha política a la situación "real" en la que se hallaba la economía del país. De igual modo, tal vez convendría también reseñar su negativa (¿nueva prueba de realismo?) a una adopción, con todas sus consecuencias, de la teoria del pacto colonial, subyacente en las propuestas de Ortiz de Landázuri.

\section{3.-El impacto "doctrinal" del voto de Magallón: su inserción en el texto del "acuerdo"}

Analizado, pues, el contenido del informe de Magallón, veamos, seguidamente y a modo de colofón, de qué forma y hasta qué punto influyó en el texto del "acuerdo" adoptado por el Consejo de Indias en la "consulta" del 14 de julio de 1777.

Como se recordará, ya la introducción de este trabajo hemos reproducido un pasaje del texto de dicho "acuerdo" en el que se afirmaba que el Consejo, pese a los votos en contra expresados por escrito de seis consejeros, habia decidido, no obstante, "conformarse" con lo expuesto por Ortiz de Landazuri en su informe y con las "reflexiones" que contenía el voto de Magallón. Puesto que el texto no especifica nada más sobre la toma de esa decisión, conviene que aclaremos por nuestra parte que a dicha reunión, además de los siete consejeros que expresaron su voto por escrito (y cuyos nombres ya conocemos), asistieron también el ministro J. Gálvez, el contador general T. Ortiz de Landázuri y otros cinco conscjeros (el marqués de Valdelirios, Marcos Ximeno. Felipe Santos, José A. Orraintia y Jacobo A. de Huerta); por consiguiente y dando por sentado que tanto Magallón como todos estos otros asistentes a la reunión que acabamos de citar votaron a favor de la ampliación del libre comercio, ello significa que el Consejo adoptó, en realidad aquella decisión por una mayoria suficiente de ocho votos contra seis. Hecha esta aclaración y volviendo al parrafo más arriba aludido, caso de no adentramos en la lectura completa del texto del "acuerdo", tal vez, podría pensarse que la referencia expresa a Magallón no cra más que una especie de deferencia hacia el único consejero que habia expresado por escrito su voto favorable. 
Sin embargo y lejos de ser así, lo cierto es que la práctica totalidad de sus reflexiones fueron incorporadas al cuerpo de dicho texto y, además, como seguidamente tendremos ocasión de comprobar, casi en su literalidad.

Por de pronto y a la hora de ponderar la importancia del asunto que se estaba tratando, el texto del "acuerdo" reproduce los mismos términos que utilizó Magallón y por idénticas razones: "El negocio es sin duda uno de los más graves, importantes y delicados en que ha podido ocuparse jamás el Consejo, por que de su decisión depende tal vez la felicidad, o la ruina del comercio de las Indias y de España, en que estriba la basa del poder y crédito de la Monarquia". Seguidamente, tras responsabilizar al exclusivismo gaditano de que el resto de las provincias españolas vivan prácticamente de espaldas a ese comercio y que, de resultas de ello, son los extranjeros quienes, en verdad, disfrutan de las riquezas de aquellos dominios, vuelve a utilizarse como prueba fehaciente el mismo ejemplo que incluyó Magallón: "Es tal en este punto nuestra desgracia, que puede asegurarse sin temor de considerable equivocación, que de los cincuenta o cincuenta y cuatro millones de pesos a que suponen hábiles calculadores montan un año con otro todo el comercio de la América, no llega a seis el que se refunde en beneficio y utilidad directa de los vasallos de V.M, pasando todos los demás tesoros que producen aquellos ricos paises a manos de los extranjeros". En el siguiente párrafo el Consejo se excusa de no entrar en el pormenor de "las circunstancias locales del Puerto de Cádiz y que resisten la calidad exclusiva de que goza" por la sencilla razón de que todo ello consta ya "en el voto de Magallón, en que se refiere con bastante individualidad". Y por idéntica razón tampoco se detendrá "en el examen de si convendrá a la Nación, en buena política, el aspirar (aún cuando le fuese posible) hacer todo o casi todo el comercio de sus Indias, atendido el estado en que se halla hoy la Europa y las Potencias extranjeras, rivales y émulas del poder de la Monarquia de V.M., ni en la exposición de los inconvenientes que resultarian de que todos los productos de nuestras minas se estancasen en la Nación, perdiendo su valor la masa numeraria a proporción de su abundancia".

Tras varias páginas dedicadas a apoyar las críticas al actual sistema y las propuestas de reforma que incluia en su informe Ortiz de Landázuri así como, también, a explicar el por qué no se había pedido opinión sobre este asunto al Consulado gaditano (al que, por cierto define como "una Compañia exclusiva de Contratación"), el texto del "acuerdo" vuelve a recurrir de nuevo a Magallón para señalar que la ampliación de la libertad comercial no perjudicaria a Cádiz: "bastantes ventajas tendria aquella plaza sobre las demás provincias del Reino, aün cuando se extendiese a éstas la libertad que se dice. Tiene aquel puerto mucha proporción para el tráfico; está vecino a provincias abundantes de caldos y fru- 
tos; hay en él casas poderosas arraigadas en el comercio que continuarian con felicidad'. Y otro tanto sucede, como puede comprobarse, a la hora de justificar la continuación del sistema de flotas a Nueva España: "deberian estas proseguir..hasta que el tiempo y la experiencia dictasen otra providencia, pues podrian resultar graves inconvenientes de suprimirlas repentinamente. Es menester; digámoslo así, un ensayo del nuevo sistema y empezar a ponerlo en ejecución sin abolir totalmente y de una vez el método actual; la experiencia del bien que vaya resultando, hará ver lo que sucesivamente se deba adelantar, caminando en todo con el mayor tiento y reflexión". Asimismo y para afianzar su dictamen en favor de la necesidad de cambiar el sistema en vigor por el de la libertad comercial, el Consejo, siguiendo también en esto a Magallón, recuerda tanto "el ejemplo de lo que practican las demás Naciones de Europa entendidas en el comercio y enriquecidas con él" como lo que en favor de dicha libertad han opinado no solo "los escritores más acreditados de las mismas Naciones" sino también "muchos de los ministros celosos de esta Monarquia, que han dejado memorias muy apreciables".

Por último y como condición indispensable que debía acompañar la ampliación del libre comercio, el Consejo hizo también suya aquella exigencia de Magallón en favor de un desarrollo paralelo de la agricultura, la industria y las comunicaciones. Concretamente lo que quedó reflejado en el texto del "acuerdo" fue lo siguiente: "que no hallándose en el dia la Nación en Estado de suministrar. lo necesario al surtimiento de nuestras colonias, deberá ocuparse incesantemente el Ministerio de V.M. con todo el empeño y celo de que es capaz en buscar los medios de multiplicar y hacer florecer las manufacturas y las artes, de animar y extender la agricultura, de aumentar la población, de facilitar por medio de buenos caminos y canales la comunicación interior y conducción de los géneros y frutos a los puertos que se señalaren: pues si no se promueven ardientemente $y$ sin intermisión todos estos importantisimos objetos, de poco servirán las demás providencias generales que puedan tomarse en punto de muestro comorcio a Indias; el mal destructivo en aquellas regiones, que es el trato ilicito de los extranjeros, subsistirá siempre mientras no se ponga la Nación en estado de suministrar a precios comodos, capaces de destruir el contrabando, la mayor parte a lo menos de lo que necesitan nuestras colonias... De aqui resulta que el Plan de la libertad de comercio que se pretende y conviene establecer no debe jamás separarse del Plan relativo al fomento de la agricultura, de las artes, de las manufacturas y de cuanto acaba de exponerse; el un sistema ha de ser inseparable del otro y asi, y no de otra manera, se prestarán un auxilio reciproco".

Visto, pues, hasta qué extremo lo esencial de las "reflexiones" incluidas por F. Magallón en su dictamen fueron asumidas en el texto del "acuerdo" claborado por el Consejo de Indias en la trascendental "consulta" del 14 de julio de 1777. 
no quisiera concluir sin reseñar un último dato que viene, asimismo, a reafirmar el carácter realmente decisivo que en nuestra opinión tuvo su voto y al que ya se hacía expresa referencia en el título de este trabajo. Me refiero, concretamente, al hecho de que ninguna de las dos propuestas de Ortiz de Landázuri con las que Magallón se mostró más crítico (recordémoslo, la prohibición general de plantar viñas en América y la libre introducción de negros) fueron incorporadas al texto del Reglamento de 12 de octubre de 1778. 